industrial and occupational diseases with a view to prevention rather than cure, and also researches into industrial fatigue and nerve strain, including systems of labour measurement in relation to shorter working hours, holidays and minimum periods for rest and recreation. 'Two sub-committees have been formed to give their attention to these subjects and a third sub-committee to deal with the effects of new industries, new materials, new uses of new processes, upon the distribution, displacement and character of labour with particular reference to plastics, textiles and non-textile products.

In view of the increasing responsibilities which scientific workers must assume for control and management in industry, the report of the Chief Inspector of Factories is a timely reminder to them of their opportunities and responsibilities in this important field.

\title{
FISHERY RESEARCH IN SCOTLAND
}

$\mathrm{T}$ $\mathrm{HE}$ passing of the Fishery Board for Scotland, under the Reorganisation of Offices (Scotland) Act, means the removal of a landmark from the field of fishery research. As the Development Commissioners observe in their latest annual report, the Board was the first department of Government in the United Kingdom to possess a permanent scientific organization, and its scientific staff was responsible for many of the earlier classical discoveries in marine research, while in more recent years it has made important contributions to the development of fishery science.

Since its inception, the Board has had its head. quarters in Edinburgh, one of the homes of the modern science of oceanography. From Edinburgh, Edward Forbes conducted much of his pioneer work of shallow-water dredging and Dr. Bruce his polar researches, and the city is for over to be associated with the famous Challenger expedition and the names of those deep-sea explorers, Sir Wyville Thomson and Sir John Mrurray. The last-named was scientific member of the Fishery Board and the chief British delegate at the International Congress held at Stockholm in 1899 - a congress which led to the formation of the International Council for the Exploration of tho Sea.

It would probably amaze some of these pioneer fishery investigators to see how far governmental interest in research, land and marine, has progressed since their time. There are many to-day who, like Forbes, would prefer to see scientific research conducted without the trammels of officialdom; but finance is a hard taskmaster and has a way of assuming the direction and control of policy. Certainly, without Government funds the conduct of marine research would, in view of the costly equipment and staff required, be a difficult undertaking for private enterprise.

It was in 1882 , following a report by a Select Committee of the House of Commons, which was impressed by the progress of fishery research in the United States, that the Fishery Board for Scotland was empowered to carry on scientific researches. The funds provided were on a modest scale, but the Board was enabled in 1886 to acquire a small steam research vessel, the Garland, which was employed mainly in investigating the effects of trawling on the inshore fisheries. With the great development of trawling, this question had become one of much public and political interest, especially in Scotland, where the inshore fisheries are of considerable importance. The investigations are described in Prof. WV. C. IrcIntosh's "Resources of the Sea", in which the author did not support the Board in the policy of restriction of trawling on which it decided.

In 1895 the Board was reconstituted, and " $a$ person of skill in the branches of science concerned with the habits and food of fishes" was thenceforward included as one of its members. 'The role was filled in turn by such distinguished men of science as Prof. Cossar Ewart, Prof. W. C. McIntosh and Sir John Murray, and since 1898 the scientific member of the Board has been Sir D'Arcy IV. Thompson, who has taken so long and honourable a part not only in fishery science but also in many other fields of culture and education.

The establishment in 1902 of the International Council for the Exploration of the Sea gave a great fillip to marine research, and the share of the pro. gramme of international research assigned to Great Britain was entrusted, so far as the northern half of the North Sea was concerned, to the Fishery Board for Scotland acting as agent for the Treasury. The work in the southern half of the North Sea was undertaken originally by the Marine Biological Association and afterwards, in 1910, by the Board (now Ministry) of Agriculture and Fisheries.

A new research vessel, the Goldseeker, was provided for the Fishery Board in 1902, and she was replaced in 1920, by means of a grant from the Development Fund, by tho research vessel Explorer, which is still in commission.

I aboratories were set up at Dunbar, Granton and Tarbert (Loch Fyne) and finally at Aberdeen, where the Board's scientific staff is now stationed. The Board has been fortunate in securing the services of a succession of scientific superintendents of outstanding ability, of whom Fulton and Bowman may bo specially mentioned. Apart from his varied contributions to fishery science, Fulton found time to write the "Sovereignty of the Sea", a valuable historical survey of questions of maritime jurisdiction, while Bowman laid the foundation for the forecasts which have now become possible of the stocks of haddock in the sea.

The statistical records of the Board are of the greatest value. Sir D'Arcy Thompson is personally responsible for $れ$ series of statistical reports on the fisheries of the North Sea, which are indispensable to any proper study and appreciation of fishery problems.

In conclusion, it is fitting to mention the contributions made by the Board to salmon and freshwater fishery research. The names of Archer, Young, Calderrood and Menzies, in turn inspectors of salmon fisheries, stand high as authorities in this branch of science.

H. J. C. 